\title{
Exploring individual and gender differences in early writing performance
}

\author{
Anne-Marie Adams ${ }^{1}$ - Fiona R. Simmons ${ }^{1}$
}

Published online: 12 May 2018

(C) The Author(s) 2018

\begin{abstract}
Boys' relatively poor progress in writing development is of particular concern in education with both cognitive and social factors proposed as possible accounts of this discrepancy. This study examined whether differences in cognitive skills such as handwriting and spelling or phonological processing abilities could explain gender differences in early writing. An opportunity sample of 116 children (52 male) ranging in age from 5:0 to 6:7 years were recruited from six UK schools. Tasks assessing vocabulary and letter knowledge, phonological awareness and phonological short-term memory skills were presented to children who were also asked to complete a number of transcription, spelling and writing tasks. Boys tended to produce shorter written compositions containing fewer correctly spelled words which were judged to be of a lower quality than texts produced by girls. However, no significant advantage for girls was identified in their vocabulary, letter knowledge or phonological processing skills, proposed as cognitive underpinnings of writing. Some relationships between phonological skills and aspects of writing differed between boys and girls and these were explored further in multiple regression analyses with gender and these phonological skills included as interaction terms. Gender predicted significant unique variance, independently of cognitive skills, in alphabet transcription and writing quality, although not dictated spelling skills. No associations between phonological skills and writing were moderated by gender. The possible role for environmental, motivational or attitudinal factors in explaining gender differences in early writing abilities should therefore perhaps be explored.
\end{abstract}

Keywords Writing · Gender differences · Phonological skills

Anne-Marie Adams

A.Adams@ljmu.ac.uk

1 School of Natural Sciences and Psychology, Liverpool John Moores University,

Liverpool L3 3AF, UK 


\section{Introduction}

Increasing standards in children's writing is a current educational priority with the apparent resistance of boys to efforts to improve their writing skills being of particular concern (Department for Education, 2012, 2013). Recent UK figures have reported that $15-19 \%$ fewer boys than girls achieved the expected standards of writing on leaving UK primary schools aged 11 years (Department for Children Schools \& Families, 2010). This is substantiated by consistent evidence of a female advantage in various national evaluations of writing performance (e.g. Department for Education, 2016; Persky, Dane, \& Jin, 2003). Analyses of the standardisation data of normed tests (Camarata \& Woodcock, 2006; Pargulski \& Reynolds, 2017; Scheiber, Reynolds, Hajovsky, \& Kaufman, 2015) also report a female advantage in spelling and writing with small to moderate effect sizes. However, individual research studies present a much less consistent pattern (see also Lee \& Al Otaiba, 2015). Whereas some studies report a significant female advantage (e.g. Babayiğit, 2015; Beard \& Burrell, 2010; Bourke \& Adams, 2011; Malecki \& Jewell, 2003; Olinghouse, 2008), others do not (e.g. Adams, Simmons, \& Willis, 2015; Jones \& Myhill, 2007; Williams \& Larkin, 2013). A first step towards understanding this variation should be the systematic exploration of factors suggested to underpin gender differences, examined using educationally relevant tools comparable to measures used for progress monitoring and identification of writing difficulties in schools (Jewell \& Malecki, 2005; Kim, Al Otaiba, Wanzek, \& Gatlin, 2015). One factor proposed to influence whether gender differences are observed or not is whether performance is judged on the basis of production-dependent measures, i.e. writing productivity, the amount that is written, or production-independent measures, i.e. writing quality, the perceived communicative value of what is produced. Gender differences tend to be found more consistently in assessments of writing productivity than writing quality (Fearrington et al., 2014; Mäki, Voeten, Vauras, \& Poskiparta, 2001). For example, although some studies have found gender differences in both writing productivity and quality (Babayiğit, 2015; Kim et al., 2015; Malecki \& Jewell, 2003; Olinghouse, 2008), others have found differences only in production-dependent measures or failed to identify gender differences based on indices of text quality (Adams et al., 2015; Jewell \& Malecki, 2005; Jones \& Myhill, 2007; Williams \& Larkin, 2013). Such inconsistencies emphasise the importance of assessing both productivity and quality on the basis of educationally valid aspects of writing performance, in any exploration of factors proposed to underpin gender differences in writing abilities.

\section{Cognitive and language processes and writing}

The Simple View of Writing (Juel, Griffith, \& Gough, 1986) identifies discrete but interrelated processes involved in producing text. Writing is achieved through the higher-level processes of setting the composition goals, generating and organising ideas and transforming these into linguistic representations, alongside lower-level proficiencies such as spelling and transcription, i.e. recording the communication in 
an observable form e.g. typing or handwriting. According to many models of writing (Berninger, Winn, MacArthur, Graham, \& Fitzgerald, 2006; McCutchen, 2000) these processes compete for limited working memory resources i.e. the ability to co-ordinate the short-term retention and manipulation of information (Baddeley, 2007; Engle, Tuholski, Laughlin, \& Conway, 1999) and restrictions in these resources are proposed to constrain the ability to produce text (Kellogg, Whiteford, Turner, Cahill, \& Mertens, 2013; McCutchen, Covill, Hoyne, \& Mildes, 1994). For the novice writer there are particular challenges; the generation of the appropriate lexical and syntactic forms, text generation, and the conversion of linguistic representations into appropriate orthographic symbols, transcription (Berninger et al., 1992; Berninger \& Swanson, 1994). The transcription skills of spelling and handwriting have been shown to be significant predictors of children's writing abilities (Abbott, Berninger, \& Fayol, 2010; Graham, Berninger, Abbott, Abbott, \& Whitaker, 1997; Kim et al., 2011). Moreover, these relationships hold not only for writing productivity (Puranik \& Al Otaiba, 2012; Wagner et al., 2011), with slow or effortful transcription constraining the amount that is written, but also writing quality (Limpo \& Alves, 2013; Wagner et al., 2011) where the association may reflect the extent to which these skills demand cognitive resources and thereby reduce resources available to support higher-level processes of generating and organising ideas (McCutchen, 2006). The impact of text generation skills on writing performance has also been observed, for example highlighting the critical role of oral language in enabling the generated ideas to be specified in an appropriate linguistic structure (Abbott \& Berninger, 1993; Dockrell, Ricketts, Charman, \& Lindsay, 2014; Kim et al., 2011; Mackie, Dockrell, \& Lindsay, 2013; see Shanahan, 2006 for a review) and may explain associations between oral language and both writing quality (Connelly, Dockrell, Walter, \& Critten, 2012; Kent, Wanzek, Petscher, Al Otaiba, \& Kim, 2014; Olinghouse, 2008) and productivity (Connelly et al., 2012) in novice writers. The success of such cognitive processes in accounting for individual differences in writing development has thus been wellestablished. Their potential to explain gender differences has yet to be fully explored.

Previous evidence revealed that factors such as oral language, spelling and transcription skills bore differential relationships with individual differences in writing quality and productivity (Kim, Al Otaiba, Folsom, Greulich, \& Puranik, 2014), however, it is not clear whether they can also explain gender differences in writing. Gender differences, favouring girls, in spelling (Allred, 1990; Babayiğit, 2015) and handwriting fluency (Berninger, Nielsen, Abbott, Wijsman, \& Raskind, 2008) have been identified, although null effects are also reported in the literature (Williams \& Larkin, 2013). Researchers have also explored the extent to which a female advantage in spelling (Babayiğit, 2015) or handwriting fluency (Kim, Al Otaiba, et al., 2015) may underpin gender differences in writing productivity and quality. Kim et al. (2015) reported that in children aged 7-8 years the effect sizes associated with gender differences in writing productivity and quality were reduced, although did not disappear, when a range of language and cognitive factors including spelling and handwriting fluency were accounted for. Notably having accounted for gender, spelling remained significantly associated with writing quality 
but not productivity suggesting that gender differences in spelling may provide an explanation for the female advantage in writing productivity. Handwriting fluency also showed differential associations with varied dimensions of writing such that having accounted for individual differences in such factors as oral language, attention and spelling, along with gender, it remained significantly associated with writing productivity and quality but not with curriculum-based measures of writing based on indices of correct word sequences in the text, suggesting that gender may mediate the relationship between transcription fluency and this aspect of writing performance. The intricacy of these findings indicates that further investigation of the role of componential writing skills such as spelling and handwriting fluency in gender differences in both text production and quality is warranted.

In addition to the more generic working memory skills relied on to control and execute writing processes (Kellogg et al., 2013; McCutchen, 1996; McCutchen et al., 1994; Swanson \& Berninger, 1996), a specific role has been proposed for phonological short-term memory (PSTM) in the text generation processes of adults (Chenoweth \& Hayes, 2003). Chenoweth and Hayes found that a secondary task which interfered with the verbal rehearsal component of PSTM (articulatory suppression) resulted in impairments in text productivity and quality. When suppressing articulation, the typed sentences of expert typists contained more errors (grammatical, spelling and typographical), even though the text was produced at a slower rate. Chenoweth and Hayes (2003) concluded that disrupting PSTM impaired the inner speech required for translation processes, specifically a writer's ability to select lexical items and arrange them into appropriate syntactic structures. The operation of this internal linguistic code underpinned by PSTM processes has been proposed to be reflected in the distinctive timing of text output comprising bursts of writing interspersed with pauses (Connelly et al., 2012; Hayes, 2012; Kaufer, Hayes, \& Flower, 1986), although transcription processes also impact on burst/pause timing in children (Alves \& Limpo, 2015; Connelly et al., 2012). Longer bursts, proposed to reflect the construction of lengthier chunks of linguistic representations available to be operated on by transcription processes, have been found to be significantly related to children's writing productivity and quality (Alves \& Limpo, 2015; Connelly et al., 2012). That such inner speech processes may also underpin gender differences in writing should be considered.

The control of inner speech displays a particular developmental trajectory. Being able to spontaneously generate a phonological code for visually presented material, as opposed to the ability to make use of an externally supplied code (Gathercole, 1998; Henry, Messer, Luger-Klein, \& Crane, 2012; Hitch, Halliday, Schaafstal, \& Heffernan, 1991), appears to be achieved between the ages of approximately 5-7 years (Hitch, Halliday, Dodd, \& Littler, 1989; Hitch, Woodin, \& Baker, 1989; Palmer, 2000b; Williams, Happé, \& Jarrold, 2008). Children's recall of sequences of pictured objects has a long history as a methodology to identify such developmental changes in PSTM performance (Flavell, Beach, \& Chinsky, 1966; Hitch et al., 1991) and is considered to be a valid index of the development of spontaneous phonological recoding of visual material in children (Henry et al., 2012). Inner speech might be expected to make a significant contribution to writing development and indeed evidence of a relationship between PSTM and children's 
writing abilities has been reported (Adams et al., 2015; Bourke \& Adams, 2010; Swanson \& Berninger, 1996). Moreover, children's ability to spontaneously apply a phonological code to remember pictures (inner speech) has been shown to predict significant unique variance in writing productivity, independently of individual differences in letter transcription skills (Adams, Simmons, Willis, \& Porter, 2013). Whether this role of inner speech in supporting the generation and retention of linguistic representations made available to transcription processes is able to explain gender differences in writing quality has yet to be explored.

\section{Gender, cognition and writing: the present study}

In the present study, the extent to which differences in the componential skills of writing, spelling and handwriting fluency, and three phonological skills are able to account for gender differences in writing abilities was evaluated. Proposals of differential cognitive processing across the genders has a long history (Hyde, 2016) and the general male and female advantage in spatial and verbal skills respectively is in common parlance (Halpern, 2012), although meta-analyses of the female verbal advantage especially conclude that these effect sizes are very small (Hedges \& Nowell, 1995; Hyde, 2014). Phonological awareness, the ability to manipulate phonological representations is closely associated with writing skills in children (Puranik \& Al Otaiba, 2012). Although inconsistent evidence of gender differences has been reported (Burt, Holm, \& Dodd, 1999; Cormier \& Dea, 1997; Hecht \& Greenfield, 2002), in a larger, more representative sample of pre-school children (Lundberg, Larsman, \& Strid, 2012) a female advantage in phonological awareness skills was observed and males also showed less improvement following phonologically based interventions. Female's better phonological awareness may therefore account for their superior writing skills.

Predominant within the adult neuroimaging literature are studies examining gender differences in verbal working memory tasks (e.g. Bell, Wilson, Wilman, Dave, \& Silverman, 2006; Goldstein et al., 2005; Lejbak, Crossley, \& Vrbancic, 2011; Schmidt et al., 2009). Far fewer have examined gender differences in PSTM and even fewer this effect in children. Gur et al. (2012) in a sample aged 8-21 years observed that females outperformed males on a test of memory for words, but not verbal working memory. A female advantage in PSTM has also been reported (e.g. Kramer, Delis, Kaplan, O’Donnell, \& Prifitera, 1997) although null effects exist too (Alloway, Gathercole, \& Pickering, 2006). In a sample directly comparable in age to the present sample, Kaushanskaya, Gross, and Buac (2013) found superior pairedassociate novel word learning in girls, but only when the strings were phonologically familiar in relation to their native language (Gathercole, Willis, Emslie, \& Baddeley, 1991). These differences, identified in the absence of gender differences in vocabulary knowledge, led the researchers to conclude that the effect arose because females were more likely to recruit long-term memory phonological representations during the task. Similar conclusions regarding the tendency to utilise phonological processes were drawn by Adams et al. (2015) relating to the differences between boys and girls in applying phonological recoding skills in writing. It is thus predicted that there may be a female advantage in both PSTM, the 
retention of externally supplied phonological information and inner speech, the ability to spontaneously generate a phonological code indexed by the ability to recall sequences of pictured objects (Henry et al., 2012) may differ between the genders.

The critical feature of the role of inner speech in writing is not oral language per se but the ability to internalise language to control, direct and support the production of the linguistic form of the text. Although inner speech has been proposed to differentiate from the development of oral language skills, specifically vocabulary (Fernyhough \& Fradley, 2005; Palmer, 2000b), vocabulary knowledge has been shown to be closely associated with children's writing development (Babayiğit, 2014; Dockrell \& Connelly, 2015; Harrison et al., 2016; Kent et al., 2014). Moreover, although dissipating through the school years (Hyde \& Linn, 1988), early female superiority in vocabulary knowledge has been identified (e.g. Berglund, Eriksson, \& Westerlund, 2005) with evidence of different heritability and environmental influences in boys and girls (Galsworthy, Dionne, Dale, \& Plomin, 2000). Although not considered to differ between the genders (Dodd \& Carr, 2003; Schneider, Roth, \& Ennemoser, 2000) as an important predictor of early literacy skills (Leppanen, Aunola, Niemi, \& Nurmi, 2008) the impact of letter knowledge was also assessed.

In conclusion, despite sometimes being elusive, when reported, gender differences in verbal skills such as phonological processing and vocabulary much more frequently represent a female advantage as discussed above. Thus gender differences favouring girls, in the transcription processes of spelling and handwriting fluency were predicted to underpin gender differences in writing productivity and quality. It was expected that phonological skills would account, at least in part, for both individual differences and gender differences in writing.

\section{Method}

\section{Participants}

Children were recruited through opportunity sampling from the Year 1 and 2 classes of six schools within the North West region of England. Data were analysed from 116 children (52 males) ranging in age from 5:0 to 6:7 years. There were 79 (37 males) Year 1 and 37 (15 males) Year 2 children. Girls and boys did not differ in age, $t(114)=.27, p>.05$ (male $M=67.88, S D=5.72$; female $M=67.59$, $S D=5.92$ in months). Due to the small sample size effects of school, classroom or teacher were not analysed.

\section{Materials}

\section{Vocabulary}

The British Picture Vocabulary Scale II (Dunn, Dunn, \& NFER-Nelson, 1997) was presented to the children. In this task the child is asked to state which of four 
pictures best represents a spoken target word. Progression criteria allow the establishment of a basal and a ceiling set and these are applied to determine the child's raw score which is reported in the current data. The raw score (see Table 1) represents a standardised score of 103 indicating a sample which was representative of the general population.

\section{Phonological awareness}

Three tests of phonological awareness were taken from the Phonological Abilities Test (Muter, Hulme, \& Snowling, 1997). In rhyme detection the child is asked to indicate which of three spoken words (accompanied by pictures) rhymes with or sounds like a target word. Three demonstration items are followed by ten test items. The total number of correctly identified rhyming pairs was recorded. The phoneme deletion test is divided into two parts. In the first the child has to delete the initial phoneme of a single syllable word resulting in a real word. In the second part the child deletes the final phoneme of a single syllable word; in this case the resulting correct response is not usually a word. For each part there are four demonstration items followed by eight test items each with an accompanying picture. The number of correctly produced items in each task was recorded. The values reported in Table 1 relate to 50th centile scores for each measure (rhyme detection $=8$; phoneme deletion at the beginning and end of words $=6$ ) indicating that this sample is representative of the population on which the test was standardised.

\section{Letter knowledge}

Taken from the Phonological Abilities Test (Muter et al., 1997) children were asked to identify by name or sound, all 26 letters of the alphabet presented individually on flashcards in a random order. The number of letters identified correctly either by name or sound was recorded.

\section{Writing assessment}

For each of the writing measures interrater reliability was assessed by the blind scoring of $20 \%$ of the sample by the second author and calculated using intraclass correlations (ICC) based on absolute agreement between the two raters.

Alphabet transcription This task closely followed the procedure of the alphabet writing task in the Wechsler Individual Achievement Test (WIAT-II UK, Wechsler, 2005). The child was presented with lined paper on which the first letter of the alphabet was written in lower case and asked to continue writing the alphabet for a period of $15 \mathrm{~s}$. The number of correctly produced letters, although it was not necessary for them to be in the correct sequence, was scored. No credit was given for capital or repeated letters or letters which were reversed. For alphabet transcription $\mathrm{ICC}=.98, p<.001$. 
Table 1 Descriptive statistics for the whole sample and as a function of gender (mean, SD, minimum and maximum values)

\begin{tabular}{|c|c|c|c|c|}
\hline \multirow[t]{2}{*}{ Measure } & \multicolumn{2}{|l|}{$\begin{array}{l}\text { Whole sample } \\
N=116\end{array}$} & \multirow{2}{*}{$\begin{array}{l}\text { Male } \\
n=52 \\
\text { Mean }(S D)\end{array}$} & \multirow{2}{*}{$\begin{array}{l}\text { Female } \\
n=64 \\
\text { Mean }(S D)\end{array}$} \\
\hline & Mean $(S D)$ & Min-max & & \\
\hline \multicolumn{5}{|l|}{ Abilities supporting writing } \\
\hline Vocabulary knowledge $\mathrm{c}^{\mathrm{c}}$ & $58.84(10.05)$ & $32-85$ & $59.90(10.11)$ & $57.99(9.99)$ \\
\hline \multicolumn{5}{|l|}{ Phonological awareness } \\
\hline Rhyme detection & $8.09(2.14)$ & $1-10$ & $8.29(2.00)$ & $7.92(2.24)$ \\
\hline Phoneme deletion (begin) & $5.92(2.33)$ & $1-8$ & $6.29(2.09)$ & $5.62(2.49)$ \\
\hline Phoneme deletion (end) & $5.35(2.47)$ & $0-8$ & $5.50(2.57)$ & $5.23(2.39)$ \\
\hline Letter knowledge & $23.95(2.28)$ & $13-26$ & $23.75(2.47)$ & $24.11(2.12)$ \\
\hline \multicolumn{5}{|l|}{ Memory skills } \\
\hline Word recall ${ }^{\mathrm{b}}$ & $21.91(3.13)$ & $12-29$ & $22.02(3.35)$ & $21.82(2.96)$ \\
\hline Picture recall & $9.72(3.87)$ & $0-16$ & $9.73(3.79)$ & $9.72(3.96)$ \\
\hline \multicolumn{5}{|l|}{ Writing assessment } \\
\hline Alphabet transcription & $5.29(3.22)$ & $0-14$ & $4.79(3.11)$ & $5.70(3.28)$ \\
\hline Spelling key words ${ }^{\mathrm{a}}$ & $4.80(2.57)$ & $0-10$ & $4.81(2.62)$ & $4.79(2.56)$ \\
\hline Spelling sounds in words & $7.54(2.24)$ & $2-11$ & $7.40(2.42)$ & $7.66(2.10)$ \\
\hline Spelling words in sentences & $5.98(3.34)$ & $0-12$ & $5.71(3.54)$ & $6.20(3.17)$ \\
\hline \multicolumn{5}{|l|}{ Text writing skills } \\
\hline Text spelling total ${ }^{\mathrm{b}}$ & $7.83(7.79)$ & $0-45$ & $5.55(6.28)$ & $9.66(8.42)$ \\
\hline Text spelling percentage ${ }^{b}$ & $14.43(7.47)$ & $0-29.17$ & $12.39(8.01)$ & $15.89(6.76)$ \\
\hline Writing productivity ${ }^{\mathrm{b}}$ & $49.54(33.29)$ & $6-203$ & $40.16(26.16)$ & $57.01(36.52)$ \\
\hline Writing quality ${ }^{\mathrm{b}}$ & $9.32(5.32)$ & $6-29$ & $7.86(3.19)$ & $10.48(6.33)$ \\
\hline
\end{tabular}

${ }^{\mathrm{a}} N=95$, male $=42$, female $=53 ;{ }^{\mathrm{b}} N=115$, male $=52$, female $=63 ;{ }^{\mathrm{c}} N=114$, male $=51$, female $=63$

Three measures of children's spelling ability were obtained; (a) Key word spelling, the ability to spell words introduced in the school curriculum, (b) spelling the component sounds in words and (c) spelling words within dictated sentences.

Key word spelling The children were asked to spell ten key words taken from the Key Stage 1 UK National curriculum current at the time of data collection, and which would have been introduced as spelling items in school. These words were; mum, big, play, this, got, come, who, you, saw, does. The number of words spelled correctly with unambiguous and correctly oriented letters, although consistent case was not required, was recorded. For this measure ICC $=.99, p<.001$.

Spelling component sounds in words The first 12 items (excluding the initial item to spell their first and last name) from the spelling test in the WIAT-II UK (Wechsler, 2005) were presented. The start point for children of this age requires children to write the letter or letter cluster which represents constituent sounds within words spoken by the experimenter and presented in the context of a sentence. 
The total number of correct items $(\max =11)$ is reported. For this measure between the two raters, ICC $=.98, p<.001$.

Spelling words in sentences Also taken from the WIAT-II UK (Wechsler, 2005) in which children are asked to write two sentences containing a total of twelve words. The sentences are dictated to the child with supporting pictures. The number of words correctly spelled is recorded. For this measure ICC $=.93, p<.001$.

Paragraph writing The procedure for paragraph writing, although not the scoring rubric, from WIAT-II UK (Wechsler, 2005) was adopted. The children were allowed $10 \mathrm{~min}$ to write to the prompt "My favourite game is...." The following indices of writing were then applied to the texts. In order to determine the transcription skills of the children, writing productivity, the total number of clearly discriminable individual letters within each text was reported. Interrater reliability for this measure recorded as ICC $=.99, p<.001$. The total number of correctly spelled words within each text, text spelling total, considered a measure of spelling productivity, was recorded. Interrater reliability for this measure indicated ICC $=.99, p<.001$. Reported also is the number of words spelled correctly as a percentage of the total number of letters produced, text spelling percentage, i.e. adjusted for the amount the children wrote. Writing quality was assessed using Big Writing, a pedagogic tool for the teaching and assessment of writing skills (Wilson, 2014, 2016). Within the suite of resources offered, Big Writing: Standards for Writing Assessment (Wilson, 2016) provides an objective measurement tool for assessing writing development. It is an adaptation of the Big Writing Scale (Wilson, 2012) modified to take account of the amended UK curriculum (Department for Education, 2013) and is hence very closely aligned with the teaching and progression of writing skills within UK schools. There are seven standards of writing specified in the scale and these range from the expectations of prewriting skills in the first year of school (aged 4 years) to standards of writing expected at the end of primary school (aged 11 years). Each child's writing was assessed against criteria reflecting a number of aspects of writing (e.g. handwriting, punctuation and grammar) listed under each standard. The majority of items $(60 \%)$ reflect vocabulary use and spelling, with $24 \%$ focused on handwriting skills, $12 \%$ on punctuation use and the smallest proportion (4\%) evaluating particular grammatical forms (specifically the use of connectives). A number of criteria in the initial reception year expectations were applicable to a teacher assessing writing development more generally within education for example "Is aware of the different processes of writing" and "Can copy over/under a model", but not appropriate to the methodology of this study. Thus 13 of the 23 Reception Year criteria were not assessed. The scale includes instances of prerequisite criteria at earlier standards to be met before evaluation of the next standard level and these requirements were abided by. However, rather than a "best fit" decision of standard attained, the number of criteria observed in each child's writing was summed and recorded. Internal reliability for the scale indexed by Cronbach's $\alpha$ was .966 . Interrater reliability for this measure revealed $\mathrm{ICC}=.98, p<.001$. 


\section{Memory skills}

Taken from the Working Memory Test Battery for Children, (Pickering \& Gathercole, 2001) word recall provided a test of PSTM. The experimenter read aloud lists of unrelated words and asked the children to recall the words in the correct serial order. Three practice trials of list length 1, 2, and 3 words were initially presented followed by six sets of words (assessment trials) at each series length starting at list length one. If a child responded correctly to the first four trials within a set the next presentation increased in length by one item and credit was awarded for the two non-presented sequences. If a child made three or more errors within a set, testing was stopped. The total number of sequences correctly recalled (trials) was reported. Based on the mean age of the sample, the mean score (see Table 1) corresponds to a standard score of 123 indicating that the children performed rather better than might be expected on this task.

Picture recall (Palmer, 2000b) assessed the extent to which children spontaneously applied a phonological code to recall visually presented material. The stimuli were taken from Hitch, Halliday et al. (1989) and comprised eight black and white line drawings of visually distinct common objects with mono-syllabic, phonologically dissimilar names. Following the procedure of (Palmer, 2000b) prior to testing four lists each comprising four items selected by random sampling without replacement were created. A further set of eight pictures provided stimuli for practise trials of three items in length. Children were initially asked to name all the pictures to ensure the single-syllable label was applied. The experimenter then explained that they should try to remember the pictures they were shown. Each drawing was placed face up on the desk between the experimenter and the child in the appropriate orientation for the child but without being named. After $2 \mathrm{~s}$ it was turned to lie face down and the next drawing in the list was placed alongside it to form a horizontal sequence. Once all the cards had been turned over the experimenter pointed to each card in the series in the order they had been presented and asked the child to name the object on the card. Following the practise trials the verbal request to recall was omitted and the gesture provided the cue to recall. Children were encouraged to guess or to say that they didn't know to ensure an answer for each item in the sequence. The total number of lists correctly recalled was recorded $(\max =16)$.

\section{Procedure}

Tasks were presented in two sessions each lasting approximately $45 \mathrm{~min}$. In the first session the picture recall, word recall, vocabulary and phonological awareness tasks were presented to each child individually. In the second session children were presented with the spelling and the writing tasks in small groups of no more than five children. Written informed consent was obtained from the parents of all children taking part and the verbal assent of the children also obtained at the time of assessment. Ethical approval was given by the Psychology Research Ethics Panel of Liverpool John Moores University wherein all aspects of the code of ethics of the 
British Psychological Society (The British Psychological Society, 2014) were abided by.

\section{Analysis strategy}

Gender differences in cognitive, memory and writing skills were explored in a series of $t$ tests. It is acknowledged, however, that for the current sample, setting power at 0.8 would require an effect size in the region of $\mathrm{d}=0.5$ to reliably detect differences. To mitigate this, bootstrapped analyses were applied and effect sizes were emphasised in these analyses. Evaluations of individual differences comprised both correlational and regression analyses.

\section{Results}

The descriptive statistics for the tests administered to the children are presented in Table 1.

Missing data were not systematically replaced in the data file, rather participants with data missing for a particular variable were excluded from analyses in which the variable was required. Writing productivity and quality had skewness statistics above 1.96, these variables and letter knowledge, rhyme detection and the number of correctly spelled words in the text also had kurtosis values above this figure. The overall sample size (and the equality across groups) was, however, considered sufficiently large to withstand any violations of normality (Field, 2013) although relevant assumptions of normality were tested. The small sample size also has implications for the power of the analyses; bootstrapping analyses are conducted where appropriate and effect sizes are emphasised in the interpretation of the following analyses.

A principal components analysis (varimax rotation) was conducted to derive a single measure of phonological awareness in order to reduce the influence of taskspecific variance. The three contributing variables were significantly intercorrelated with coefficients ranging from .35 to .70 (all $p \mathrm{~s}<.001$ ) and the Kaiser-MeyerOlkin measure verified the sampling adequacy for the analysis, $\mathrm{KMO}=.61$ (mediocre according to Hutcheson \& Sofroniou, 1999). Bartlett's test of sphericity, $\chi^{2}(3)=106.13, p<.001$, indicated that the correlation between the tests was sufficiently large for PCA. The resulting phonological awareness variable explained $67.79 \%$ of the variance in the three component tests.

A further principal components analysis (varimax rotation) was conducted to derive a single measure of dictated spelling, spelling of items for which the phonological form is provided in the administration of the task. The three contributing variables; Key word spelling, spelling component sounds in words and spelling words in sentences were significantly intercorrelated with coefficients ranging from .41 to .69 , all $p \mathrm{~s}<.001$. The Kaiser-Meyer-Olkin measure verified the sampling adequacy for the analysis, $\mathrm{KMO}=.64$ (mediocre according to Hutcheson \& Sofroniou, 1999). Bartlett's test of sphericity, $\chi^{2}(3)=88.65, p<.001$, indicated that the correlation between the tests was sufficiently large for PCA. The 
resulting dictated spelling variable explained $69.52 \%$ of the variance in the three component tests.

\section{Group differences}

A series of independent $t$ tests (with the familywise error rate set at $1 \%$ to account for multiple comparisons) examined gender differences in the measures (see Table 2). No significant differences were identified in either vocabulary, phonological awareness or the recall of words or pictures. The associated effect sizes were also negligible. Similarly boys and girls recognised a comparable number of letters, although this is likely to reflect a ceiling effect in both groups. They could transcribe a similar number of letters in $15 \mathrm{~s}$ and their dictated spelling skills did not differ. For all the above measures the significance associated with Levene's test for equality of variance across groups was greater than 5\% indicating that this assumption had not been violated. In addition, bootstrapped confidence intervals for the differences between the means revealed that mean differences in the population likely span zero and therefore confirm the conclusion that gender does not impact significantly on these measures. However, a rather different picture emerged for assessments of text composition. Significant gender differences reflecting a female advantage were identified in writing productivity, text spelling total and percentage and the quality of the children's compositions (all $p s<.01$ ). This significant female advantage was found consistently in each of the bootstrapped confidence intervals for the differences between the means which never crossed zero. The effect sizes associated with these contrasts, although categorised as small (Cohen, 1992), might be

Table 2 Gender differences in cognitive, memory and writing skills

\begin{tabular}{|c|c|c|c|c|}
\hline Measure & $t$ & $p$ & Bootstrapped mean difference $\mathrm{BCa} 95 \% \mathrm{CI}$ & Effect size $(r)$ \\
\hline \multicolumn{5}{|l|}{ Abilities supporting writing } \\
\hline Vocabulary knowledge & 1.01 & .31 & {$[-2.18,6.06]$} & .09 \\
\hline Phonological awareness & 1.19 & .24 & {$[-0.17,0.68]$} & .11 \\
\hline Letter knowledge & -0.84 & .40 & {$[-1.35,0.61]$} & .08 \\
\hline \multicolumn{5}{|l|}{ Memory skills } \\
\hline Word recall & 0.33 & .74 & {$[-0.99,1.37]$} & .03 \\
\hline Picture recall & 0.02 & .99 & {$[-1.39,1.48]$} & .01 \\
\hline \multicolumn{5}{|l|}{ Writing assessment } \\
\hline Alphabet transcription & -1.53 & .13 & {$[-2.07,0.31]$} & .14 \\
\hline Dictated spelling & -.73 & .46 & {$[-.57, .28]$} & .08 \\
\hline Text spelling total & -2.90 & .005 & {$[-6.72,-1.55]$} & $.26^{*}$ \\
\hline $\begin{array}{r}\text { Text spelling } \\
\text { percentage }\end{array}$ & -2.31 & .023 & {$[-6.49,-.489]$} & $.23 *$ \\
\hline Writing productivity & -2.77 & .006 & {$[-30.25,-4.45]$} & $.25^{*}$ \\
\hline Writing quality & -2.89 & .005 & {$[-4.40,-0.85]$} & $.26^{*}$ \\
\hline
\end{tabular}


considered to approach a moderate size. Although Levene's analysis for the equality of group variance was only significant for writing quality (statistics for equal variance not assumed are reported in Table 2), it should be noted that significance values for both writing productivity and text spelling total approached 5\% (.051 and .08 respectively). Reference to the standard deviations in Table 1 indicates that there was a trend for greater variation in the female than the male sample with inspection of the distributions confirming a larger proportion of girls scoring highly.

\section{Correlational analyses}

Pearson correlation coefficients were conducted to identify relationships between writing skills and the vocabulary and letter knowledge, phonological awareness, and memory variables. BCa bootstrap 95\% confidence intervals are also reported for significant correlations when the lower bound falls below the critical value of .179 suggesting caution in interpreting the significance of these associations.

Children's vocabulary skills were related to their ability to spell to dictation (see Table 3) although the lower bound $95 \%$ confidence interval coefficient for the later was .121 and hence below the critical value for this sample size. There was, however, no significant association between vocabulary knowledge and the text composition indices of writing productivity, text spelling total and percentage or writing quality. Letter knowledge bore a significant relationship only with dictated spelling and text spelling percentage. Significant associations were also identified between children's phonological awareness skills and transcription and spelling skills and also text quality, although not with writing productivity and text spelling total. The lower bound $95 \%$ confidence interval coefficient for alphabet transcription was .02, however. Word and picture recall evidenced similar patterns of associations with writing performance. Both bore significant associations with dictated spelling (although the lower bound 95\% confidence intervals fell below the critical value, .03 and .06 respectively). Neither word nor picture recall bore significant association with alphabet transcription, writing productivity, spelling

Table 3 Pearson correlation coefficients between abilities supporting writing, phonological skills and writing abilities across the whole sample

\begin{tabular}{|c|c|c|c|c|c|}
\hline & Vocabulary & $\begin{array}{l}\text { Letter } \\
\text { knowledge }\end{array}$ & $\begin{array}{l}\text { Phonological } \\
\text { awareness }\end{array}$ & $\begin{array}{l}\text { Word } \\
\text { recall }\end{array}$ & Picture recall \\
\hline $\begin{array}{l}\text { Alphabet } \\
\text { transcription }\end{array}$ & .12 & .15 & $.21^{*}$ & .04 & .02 \\
\hline Dictated spelling & $.32^{* *}$ & $.42 * *$ & $.49^{* *}$ & $.23 *$ & $.25^{*}$ \\
\hline Writing productivity & .08 & -.03 & .01 & .11 & .04 \\
\hline Text spelling total & .13 & -.02 & .12 & .11 & .06 \\
\hline $\begin{array}{c}\text { Text spelling } \\
\text { percentage }\end{array}$ & -.19 & $.25^{*}$ & $-.39 * *$ & .09 & -.19 \\
\hline Writing quality & .19 & .11 & $.21 *$ & .19 & .16 \\
\hline
\end{tabular}

$* p<.05 ; * * p<.01$ 
total or percentage or writing quality. Within the whole sample, therefore, the most consistent relationships with writing performance were found with phonological awareness. Relationships were also more frequently found with dictated spelling than with indices of text composition. These relationships were also evaluated within each gender (see Table 4).

The pattern of significant associations identified in the whole sample were broadly replicated within both genders, although there were exceptions including some where the pattern differed for males and females. For example significant relationships in the whole sample between dictated spelling, vocabulary knowledge, word and picture recall were not observed in the male sample although they remained significant in the female sample. A similar pattern was identified for the relationships between phonological awareness and writing quality. In contrast the significant relationship between phonological awareness and alphabet transcription in the whole sample remained in the male sample but was no longer significant in the female sample. Furthermore, although the association between picture recall and writing quality was not significant in the whole sample it was significant in the male but not the female sample.

\section{Regression analyses}

These suggestions of differential relationships within males and females between abilities proposed to support writing development and writing performance were explored further in a series of multiple regressions. The criterion variables examined were those which revealed for at least one of the predictors, a significant relationship in one gender but not the other. Thus the criterion variables of alphabet transcription, dictated spelling and writing quality were assessed (see Table 5). These regressions were structured such that at Step 1 age, vocabulary knowledge and letter knowledge were entered as predictors to control for gender differences in these skills (Reynolds, Scheiber, Hajovsky, Schwartz, \& Kaufman, 2015). At Step 2 the inclusion of word and picture recall and phonological awareness allowed their relative predictive power to be assessed. Gender was entered at Step 3 to determine whether gender explained further additional variance. Finally, at Step 4 interaction terms representing the interaction of gender with the phonological skill displaying different relationships in males and females was included. This final step therefore assesses whether gender is a moderator of the relationship between a particular phonological skill and the index of writing and is thus a very stringent test of whether the relationships really were different in males and females. These analyses were bootstrapped to bias corrected and accelerated confidence interval using 1000 samples in order to minimise the impact of any deviations from normality of the data (Field, 2013).

With the criterion variable of alphabet transcription the variables entered at Step 1 were able to account for $3.5 \%$ of the variance, $F(3,110)=1.34, p>.05$. An additional $5.3 \%$ of variance was accounted for at Step $2, F(3,107)=2.06, p>.05$. Inspection of the beta coefficients revealed that only the coefficient related to phonological awareness was significant $(p=.024)$. At Step 3 gender predicted significant further variance $(3.7 \%), F(1,106)=4.45, p=.04$. The interaction term 


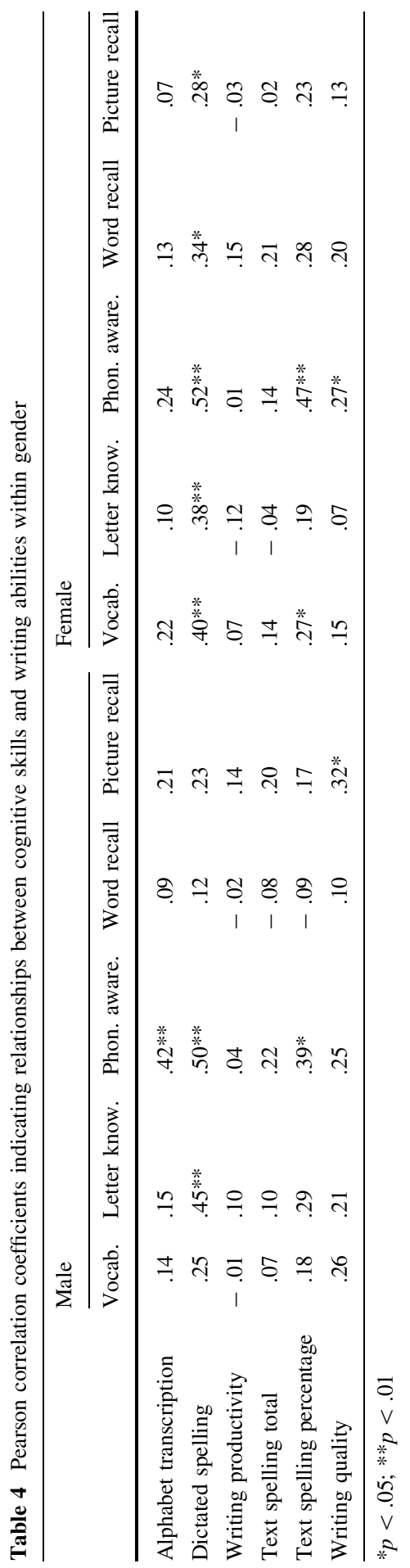







did not contribute significant additional variance $(0.7 \%), F(1,105)=0.82, p>.05$. Indeed the final model accounted for only $13.2 \%$ of the variance in alphabet transcription and just failed to reach traditional levels of significance, $F(8$, $105)=1.98, p=.055$.

With dictated spelling as the criterion variable the variables entered at Step 1 were able to account for $29.3 \%$ of the variance, $F(3,89)=12.29, p<.001$. The coefficients of both age and letter knowledge were significant at this step. A nonsignificant proportion $(3.1 \%)$ of additional variance was accounted for at Step 2, $F(3,86)=1.33, p>.05$, although the coefficient related to phonological awareness only just failed to reach traditional levels of significance $(p=.053)$. The proportion of additional variance accounted for at Step 3 when gender was introduced to the model $(1.6 \%)$, was also not significant, $F(1,85)=2.01, p>.05$. The interaction terms entered at Step 4 also failed to contribute significant additional variance $(2.7 \%), F(2,83)=1.76, p>.05$. Nevertheless, together all the variables predicted a significant $36.7 \%$ of the variance in dictated spelling performance, $F(9,83)=5.34$, $p<.001$.

The final set of regressions comprised writing quality as the criterion variable. At Step 1 only $4.1 \%$ of the variance was accounted for, $F(3,109)=12.29, p>.05$. A further $2.6 \%$ of variance was accounted for at Step 2, although this was not significant, $F(3,106)=0.97, p>.05$. Gender entered at Step 3 was able to account for a further $8.4 \%$ of the variance, $F(1,105)=10.44, p=.002$. However, the interaction terms entered at Step 4 contributed only $0.6 \%$ of variance, $F(2$, $103)=0.36, p>.05$. Together all the variables predicted a significant $15.7 \%$ of the variance in writing quality, $F(9103)=2.13, p=.034$.

\section{Discussion}

The aim of the current study was to examine the extent to which the transcription skills of spelling and handwriting fluency and phonological skills were able to predict both individual and gender differences in writing performance. Despite girls demonstrating an advantage in text composition, they did not outperform boys in transcription skills or their phonological skills which thus adds to the narrative of inconsistent findings in this area (Adams et al., 2015; Babayiğit, 2015; Beard \& Burrell, 2010; Williams \& Larkin, 2013). Within the whole sample, phonological skills along with vocabulary and letter knowledge, were not associated with text composition skills (with the exception of phonological awareness and writing quality and text spelling percentage accuracy), although they were all related to dictated spelling performance. There were apparent differences in within gender associations between writing performance and some of these skills. However, although gender continued to account for significant variance over and above these skills in both alphabet transcription and writing quality, gender was not a moderator of the relationships between phonological skills and writing performance. Therefore these associations should not be considered different across the genders. The implications of these patterns are considered below. 


\section{Transcription skills: handwriting fluency and spelling}

Alphabet transcription was significantly associated only with phonological awareness. It is perhaps surprising that alphabet transcription skills were unrelated to text composition in our sample, as alphabet transcription speed has been shown to be an important predictor of writing abilities, especially in the early stages of writing development (Berninger, Cartwright, Yates, Swanson, \& Abbott, 1994). Variations in modes of production, e.g. cursive and manuscript handwriting versus keyboarding, have, however, displayed different relationships with spelling and writing skills (Alstad et al., 2015) and also vary in their relationships with other popular modes of handwriting fluency assessment such as sentence copying (Kim, Park, \& Park, 2015; Wagner et al., 2011). Such contrasts highlight the need for further research to understand the processes underpinning transcription tasks and their role in writing performance (Alstad et al., 2015).

Dictated spelling bore significant associations with vocabulary and letter knowledge, phonological awareness and memory for words and pictures. These findings are consistent with the wealth of evidence that has highlighted the close relationships between both vocabulary knowledge and phonological awareness and spelling development (Fraser \& Conti-Ramsden, 2008; Johnston, McGeown, \& Moxon, 2014; Kent et al., 2014; Kim et al., 2011; Lee \& Al Otaiba, 2015; Ouellette \& Sénéchal, 2008; Puranik \& Al Otaiba, 2012; Puranik, Lonigan, \& Kim, 2011). Verbal short-term memory and verbal recoding skills have also been shown to be related to spelling development (Adams et al., 2013; Caravolas, Hulme, \& Snowling, 2001; Ouellette \& Sénéchal, 2008; Palmer, 2000a).

\section{Text composition}

In contrast to dictated spelling however, indices of children's abilities to compose texts, both in terms of productivity and quality were not associated with vocabulary, letter knowledge, phonological awareness or memory for words or pictures. The only exceptions to this were the significant relationship between phonological awareness and both text spelling percentage and writing quality, suggesting that phonological awareness is more strongly related to aspects of the quality rather than the quantity of writing. This lack of a relationship between writing performance and vocabulary and memory skills appears to be at odds with previous research which has reported significant associations between for example vocabulary knowledge and writing productivity (Kim et al., 2011; Puranik \& Al Otaiba, 2012) and also writing quality (Kent et al., 2014). However, closer inspection reveals that although categorised as significant in their large sample sizes $(n>240)$, the correlation coefficients are small, ranging from .15 to .25 . It may therefore be that broadly comparable relations underlie the present data, although the sample size may limit the ability to identify significant associations in the present study. It should also be noted, that in contrast to other studies, in order to explore the factors underpinning gender differences reported in educational statistics, here an index of writing closely aligned to curriculum assessment was adopted. It is therefore important to replicate this study in a larger sample to provide clarification of these issues. 
The current pattern of differential relationships with vocabulary and letter knowledge, phonological awareness and memory skills, suggests that the dictated spelling of individual words and the creation of texts, including the accuracy of spelling within those texts, may rely on different cognitive processes. Consistent with this Harrison et al. (2016) showed that although speeded naming of letters predicted the accuracy of spelling in written compositions, it was not a significant predictor of single word spelling. This contention that spelling to dictation and the production of self-generated text may rely on different processes has some support in the literature evaluating writing in a second language. The impact of writing in a second language has been shown to be different for spelling and text generation, with text generation processes being more heavily dependent on oral language skills (Babayiğit, 2014; Cameron \& Besser, 2004). Furthermore Babayiğit (2015) found gender differences in both L1 and L2 writers such that girls wrote longer texts which were also judged to be of a higher quality than boys, even when gender differences in spelling single words was taken into account. This research suggests that the processes underpinning the spelling of dictated individual words and text generation processes can be discriminated and is supported by the current evidence of differential associations between cognitive skills and dictated spelling compared to indices of independently generated text.

Given that gender differences are more consistently identified in writing productivity than in writing quality (Adams et al., 2015; Jewell \& Malecki, 2005; Jones \& Myhill, 2007; Williams \& Larkin, 2013), both these aspects of writing performance were assessed in the present study. Gender differences were observed in both writing productivity and quality with boys producing written texts that contained fewer discernible letters, fewer correctly spelled words and which were judged to be of a poorer quality than the texts produced by girls. This pattern of gender differences is consistent with a number of previous studies (Babayiğit, 2015; Bourke \& Adams, 2011; Kim et al., 2015; Malecki \& Jewell, 2003). Although gender differences favouring females in text composition were observed in the present data no significant gender differences were identified in any of the cognitive skills proposed to underpin writing development; vocabulary and letter knowledge, phonological awareness, word or picture recall, nor in any of the component skills of extended writing; alphabet transcription and spelling. Although significant gender differences in some of these skills have been reported previously (Adams et al., 2013; Babayiğit, 2015; Below, Skinner, Fearrington, \& Sorrell, 2010; Berninger et al., 2008) other studies have failed to identify an effect of gender on these measures. For instance Adams et al. (2015) found no significant gender differences in alphabet transcription, and Williams and Larkin (2013) did not observe gender differences in PSTM, phonological awareness or dictated spelling. Clearly there is not a simple account of the relationship between factors such as oral language and working memory (Arfé, Dockrell, \& De Bernardi, 2016; Connelly et al., 2012; Kim et al., 2011; McCutchen et al., 1994), the componential skills of writing such as spelling and handwriting fluency (Connelly et al., 2012; Olinghouse, 2008) which are believed to predict individual differences in writing development, and gender differences in writing. One factor likely to contribute to inconsistency in the research evidence and the conclusions drawn is the stage of writing development of 
the children. This is likely to have an impact on factors explaining both individual and gender differences in writing and will require systematic investigation to present a comprehensive account.

\section{Phonological skills and writing}

An exception to the lack of association between writing performance and the assessed cognitive skills was the significant relationship between writing quality and phonological awareness. Significant associations have previously been identified between phonological awareness and writing quality (Berninger et al., 1994; Dockrell \& Connelly, 2015) and although associations with productivity have been reported (Puranik \& Al Otaiba, 2012), as in the present study, sometimes they have not been identified (Berninger et al., 1994). Phonological awareness may, therefore, be more closely related to the quality of what is written than to the amount of writing produced. Surprisingly few studies have compared such associations nor has research directly contrasted the predictive value of the ability to manipulate sounds in spoken language against the ability to generate or retain phonological information in STM as in the present study.

Significant associations between phonological short-term and working memory and writing are often (Adams et al., 2013, 2015; Berninger et al., 1994; Bourke, Davies, Sumner, \& Green, 2014), but not always (Bourke \& Adams, 2003; Williams \& Larkin, 2013) identified. Mirroring the lack of association in the current data, Williams and Larkin (2013) found that PSTM was not significantly related to indices of writing productivity. They ascribed this lack of association to their use of a picture prompt to generate writing which may have lessened the memory load of the writing task. However, the present findings with a verbal writing prompt suggest that the association may in fact be weaker than generally perceived, particularly when considering the productivity of very young writers. One possible account could be that visual memory skills may be a critical feature of the text production skills of novice writers. Bourke et al. (2014) showed that visuo-spatial working memory skills predicted a significant proportion of unique variance in the writing quality of children beginning to master this skill. A further issue may be that commonly within the literature the role of phonological STM as distinct from working memory which incorporates not only the retention but also the processing of verbal information along with aspects of attentional control, is often not evaluated in isolation (Berninger et al., 1994; Dockrell et al., 2014; Vanderberg \& Swanson, 2007). In order to clarify the role that specifically the short-term storage of verbal information, proposed to be important in the writing skills of expert writers (Chenoweth \& Hayes, 2003; see Olive, 2004 for a review), as distinct from the attentional resources indexed in working memory tasks, may play in the writing performance of those mastering the skill requires systematic exploration of these skills using discrete measures of the implicated cognitive constructs and directly contrasting various writing task prompts.

A further aim of the present study was to explore whether a novel componential writing skill, the ability to generate an inner voice, differentially underpinned the writing performance of boys and girls. It was proposed that in a manner similar to 
that in adults (Chenoweth \& Hayes, 2003) there may be individual and gender differences in the use of an inner voice to support the translation processes of novice writers (Berninger \& Swanson, 1994). The relative ability of this skill to explain variance in writing performance over PSTM and phonological awareness was therefore contrasted. The regression analyses revealed that phonological awareness was the only significant predictor of alphabet transcription and was the most promising predictor of dictated spelling. Unexpectedly, none of the phonological measures was able to contribute unique variance to writing quality. Nor were any of the associations with writing productivity or text spelling total significant. With respect to the skills of inner speech generation associated with picture recall, this pattern was in contrast to previous evidence demonstrating that this skill was related to differences in writing productivity (Adams et al., 2013). One account of this discrepancy may be the evaluation in the present study of the relationship independently of vocabulary knowledge which was not controlled for in Adams et al. (2013). Thus although inner speech is considered distinct from vocabulary knowledge (Fernyhough \& Fradley, 2005) the unique aspect of inner speech may not be sufficient to reveal independent associations with writing performance. Given proposals that novice writers may rely to a greater extent on visual skills (Bourke et al., 2014) it may be that the association between inner speech and writing found in adults (Chenoweth \& Hayes, 2003) may not be evident in novice writers. Developmental increases in burst length (Alves \& Limpo, 2015) are consistent with this position. Future research should therefore evaluate the developmental trajectory of the use of inner speech in children's writing.

\section{Alternative factors in gender differences in writing}

Gender continued to explain significant variance in alphabet transcription and writing quality after the contributions of vocabulary, letter knowledge and each of the phonological skills had been accounted for. A similar pattern was reported in a recent large scale, latent variable model-based analysis of gender differences in both spelling and writing across childhood (Reynolds et al., 2015) in which girls continued to perform better than boys even after differences in crystallised intelligence, fluid reasoning and visual processing had been controlled. Reynolds et al. (2015) note that it is difficult from their data to pinpoint the factors which may explain the gender differences they identified but acknowledge the role that higher order skills, for example self-regulation strategies (Graham \& Harris, 2000) may play. Other factors should also be considered for example, differences in attitudes towards writing (Knudson, 1995), self-efficacy (Klassen, 2002; Meece, Glienke, \& Burg, 2006) or motivation (Mata, 2011; Pajares \& Valiante, 2001), girls' superiority in fine motor skills development (Morley, Till, Ogilvie, \& Turner, 2015) or aspects of the environment, for example in kindergarten with free choice girls spent more time engaging in activities classified as relating to language and literacy and arts than did boys, but less time than boys in science-based activities (Early et al., 2010). It may be premature to dismiss the role of cognitive factors such as those addressed in the present study which appear critical in explaining individual differences in writing development, as a basis for gender differences in writing skills on the 
evidence of a single study. Thus directly comparing cognitive and non-cognitive factors and the development of writing skills in boys and girls is an important priority for future research. Longitudinal analyses which examine the interactions between cognitive and non-cognitive factors over the course of writing development would be most beneficial.

\section{Limitations}

A number of limitations of the study could be usefully addressed in future research. This was an exploratory study, questioning whether those factors proposed to underpin developmental differences in writing might also explain gender differences. As such it highlighted a number of interesting avenues for future research. It should, however, be explicitly acknowledged that the study is underpowered although bootstrapped analyses and a focus on effect sizes aimed to mitigate this issue. Nevertheless, the conclusions about the presence or absence of group differences should be considered tentative until a large scale replication can be achieved.

The proportions of variance explained by the current predictors appeared quite small, e.g. for alphabet transcription $13.2 \%$ and writing quality $15.7 \%$. Previous studies which have reported the total variance accounted for have reported figures more similar to the $36.7 \%$ of the variance explained in dictated spelling. For example, (Arfé et al., 2016; Kent et al., 2014; Kim et al., 2015) explained between 30 and $49 \%$ of the variance in the productivity or quality of young children's texts. However, these studies included as predictors either measures of executive function/working memory, language measures beyond vocabulary knowledge e.g. the ability to orally generate sentences and comprehension of syntactic structures, or either reading or listening comprehension. It may be that such discourse level oral language skills account for the major proportion of variance in extended prose composition in children and perhaps also gender differences.

In some cultural contexts the expectations of extended writing by children of this age may seem optimistic. However, the UK National Curriculum attainment targets specified by the programme of study (Department for Education, 2013) indicate that by the end of Year 1 the expectations are that children will produce sequences of sentences to form short narratives, reviewing these to check meaning and include the emerging ability to apply a range of punctuation marks to delineate sentences. By the end of Year 2 children may be expected to expand upon these skills by writing narratives about personal experiences and other real events and writing for different purposes including developing a 'stamina for writing' (p21). In the present study, all children were encouraged to continue to write for the allotted time (10 min.), although children differed in their application to this task. Unfortunately data was not recorded regarding whether boys finished writing earlier than girls, and hence whether their lesser productivity may reflect reduced stamina for writing. Nevertheless for the children in this study writing a paragraph was a familiar curriculum task, although they differed markedly in their ability to meet the expectations of the task. 


\section{Conclusion}

This study explored differences in the component skills of writing and the extent to which the retention and manipulation of phonological information explained individual and gender differences in writing development. Although the text composition skills of girls exceeded that of boys, these were not accompanied by gender differences in a number of componential skills of writing, nor in cognitive skills proposed to underpin individual differences in writing development. Gender continued to explain additional significant variance in writing performance over and above these skills. Directly contrasting cognitive and noncognitive factors which may underpin gender differences in writing development is considered an important priority for future research.

Open Access This article is distributed under the terms of the Creative Commons Attribution 4.0 International License (http://creativecommons.org/licenses/by/4.0/), which permits unrestricted use, distribution, and reproduction in any medium, provided you give appropriate credit to the original author(s) and the source, provide a link to the Creative Commons license, and indicate if changes were made.

\section{References}

Abbott, R. D., \& Berninger, V. W. (1993). Structural equation modeling of relationships among developmental skills and writing skills in primary-and intermediate-grade writers. Journal of Educational Psychology, 85(3), 478. https://doi.org/10.1037/0022-0663.85.3.478.

Abbott, R. D., Berninger, V. W., \& Fayol, M. (2010). Longitudinal relationships of levels of language in writing and between writing and reading in grades 1 to 7. Journal of Educational Psychology, 102(2), 281. https://doi.org/10.1037/a0019318.

Adams, A.-M., Simmons, F., \& Willis, C. (2015). Exploring relationships between working memory and writing: Individual differences associated with gender. Learning and Individual Differences, 40, 101-107. https://doi.org/10.1016/j.lindif.2015.04.011.

Adams, A. M., Simmons, F. R., Willis, C. S., \& Porter, S. (2013). The impact of the development of verbal recoding on children's early writing skills. British Journal of Educational Psychology, 83(1), 76-97. https://doi.org/10.1111/j.2044-8279.2011.02056.x.

Alloway, T. P., Gathercole, S. E., \& Pickering, S. (2006). Verbal and visuospatial short-term and working memory in children: Are they separable? Child Development, 77(6), 1698-1716. https://doi.org/10. 1111/j.1467-8624.2006.00968.x.

Allred, R. A. (1990). Gender differences in spelling achievement in grades 1 through 6. The Journal of Educational Research, 83(4), 187-193. https://doi.org/10.1080/00220671.1990.10885955.

Alstad, Z., Sanders, E., Abbott, R. D., Barnett, A. L., Henderson, S. E., Connelly, V., et al. (2015). Modes of alphabet letter production during middle childhood and adolescence: Interrelationships with each other and other writing skills. Journal of Writing Research, 6(3), 199. https://doi.org/10.17239/jowr2015.06.03.1.

Alves, R. A., \& Limpo, T. (2015). Progress in written language bursts, pauses, transcription, and written composition across schooling. Scientific Studies of Reading, 19(5), 374-391. https://doi.org/10.1080/ 10888438.2015.1059838.

Arfé, B., Dockrell, J. E., \& De Bernardi, B. (2016). The effect of language specific factors on early written composition: The role of spelling, oral language and text generation skills in a shallow orthography. Reading and Writing, 29(3), 501-527. https://doi.org/10.1007/s11145-015-9617-5.

Babayiğit, S. (2014). The role of oral language skills in reading and listening comprehension of text: A comparison of monolingual (L1) and bilingual (L2) speakers of English language. Journal of Research in Reading, 37(S1), S22-S47. https://doi.org/10.1007/s11145-013-9482-z.

Babayiğit, S. (2015). The dimensions of written expression: Language group and gender differences. Learning and Instruction, 35, 33-41. https://doi.org/10.1016/j.learinstruc.2014.08.006. 
Baddeley, A. (2007). Working memory, thought, and action. Oxford: Oxford University Press.

Beard, R., \& Burrell, A. (2010). Investigating narrative writing by 9-11-year-olds. Journal of Research in Reading, 33(1), 77-93. https://doi.org/10.1111/j.1467-9817.2009.01433.x.

Bell, E. C., Wilson, M. C., Wilman, A. H., Dave, S., \& Silverman, P. H. (2006). Males and females differ in brain activation during cognitive tasks. Neuroimage. https://doi.org/10.1016/j.neuroimage.2005. 09.049.

Below, J. L., Skinner, C. H., Fearrington, J. Y., \& Sorrell, C. A. (2010). Gender differences in early literacy: Analysis of kindergarten through fifth-grade dynamic indicators of basic early literacy skills probes. School Psychology Review, 39(2), 240.

Berglund, E., Eriksson, M., \& Westerlund, M. (2005). Communicative skills in relation to gender, birth order, childcare and socioeconomic status in 18-month-old children. Scandinavian Journal of Psychology, 46, 485-491. https://doi.org/10.1111/j.1467-9450.2005.00480.x.

Berninger, V. W., Cartwright, A. C., Yates, C. M., Swanson, H. L., \& Abbott, R. D. (1994). Developmental skills related to writing and reading acquisition in the intermediate grades. Reading and Writing, 6(2), 161-196. https://doi.org/10.1007/BF01026911.

Berninger, V. W., Nielsen, K. H., Abbott, R. D., Wijsman, E., \& Raskind, W. (2008). Gender differences in severity of writing and reading disabilities. Journal of School Psychology, 46(2), 151-172. https:// doi.org/10.1016/j.jsp.2007.02.007.

Berninger, V. W., \& Swanson, H. L. (1994). Modifying Hayes and Flower's model of skilled writing to explain beginning and developing writing. In J. S. Carlson \& E. C. Butterfield (Eds.), Advances in cognition and educational practice, children's writing: Toward a process theory of the development of skilled writing (Vol. 2, pp. 57-81). Greenwich, CT: JAI Press.

Berninger, V. W., Winn, W., MacArthur, C., Graham, S., \& Fitzgerald, J. (2006). Implications of advancements in brain research and technology for writing development, writing instruction, and educational evolution. In S. G. J. F. E. C. MacArthur (Ed.), Handbook of writing research (pp. 96-114). New York, NY: Guilford.

Berninger, V., Yates, C., Cartwright, A., Rutberg, J., Remy, E., \& Abbott, R. (1992). Lower-level developmental skills in beginning writing. Reading and Writing, 4(3), 257-280. https://doi.org/10. 1007/BF01027151.

Bourke, L., \& Adams, A.-M. (2003). The relationship between working memory and early writing assessed at the word, sentence and text level. Educational and Child Psychology, 20(3), 19-36.

Bourke, L., \& Adams, A. M. (2010). Cognitive constraints and the early learning goals in writing. Journal of Research in Reading, 33(1), 94-110. https://doi.org/10.1111/j.1467-9817.1009.01434.x.

Bourke, L., \& Adams, A.-M. (2011). Is it differences in language skills and working memory that account for girls being better at writing than boys. Journal of Writing Research, 3(3), 249-277.

Bourke, L., Davies, S. J., Sumner, E., \& Green, C. (2014). Individual differences in the development of early writing skills: Testing the unique contribution of visuo-spatial working memory. Reading and Writing, 27(2), 315-335.

Burt, L., Holm, A., \& Dodd, B. (1999). Phonological awareness skills of 4-year-old British children: An assessment and developmental data. International Journal of Language \& Communication Disorders, 34, 311-335. https://doi.org/10.1089/136828299247432.

Camarata, S., \& Woodcock, R. (2006). Sex differences in processing speed: Developmental effects in males and females. Intelligence, 34, 231-252. https://doi.org/10.1016/j.intell.2005.12.001.

Cameron, L., \& Besser, S. (2004). Writing in English as an additional language at Key Stage 2. Research Report No. 586. London: Department for Education and Skills

Caravolas, M., Hulme, C., \& Snowling, M. J. (2001). The foundations of spelling ability: Evidence from a 3-year longitudinal study. Journal of Memory and Language, 45(4), 751-774. https://doi.org/10. 1006/jmla-2000.2785.

Chenoweth, N. A., \& Hayes, J. R. (2003). The inner voice in writing. Written Communication, 20(1), 99-118. https://doi.org/10.1177/0741088303253572.

Cohen, J. (1992). A power primer. Psychological Bulletin, 112(1), 155.

Connelly, V., Dockrell, J. E., Walter, K., \& Critten, S. (2012). Predicting the quality of composition and written language bursts from oral language, spelling, and handwriting skills in children with and without specific language impairment. Written Communication, 29(3), 278-302. https://doi.org/10. $1177 / 0741088312451109$.

Cormier, P., \& Dea, S. (1997). Distinctive patterns of relationship of phonological awareness and working memory with reading development. Reading and Writing: An Interdisciplinary Journal, 9, 193-206. https://doi.org/10.1023/A:100793272. 
Department for Children Schools and Families. (2010). Early years foundation stage profile achievement by pupil characteristics, England 2008/2009. Retrieved from London.

Department for Education. (2012). What is the research evidence on writing? RR238. Retrieved from https://www.gov.uk/government/publications/what-is-the-research-evidence-on-writing. Accessed 11 May 2018.

Department for Education. (2013). The national curriculum in England framework document. September 2013, ref: DFE-00178-2013. Retrieved from https:/www.gov.uk/government/publications/nationalcurriculum-in-england-primary-curriculum\#history. Accessed 11 May 2018.

Department for Education. (2016). Provisional GCSE and equivalent results in England, 2015 to 2016 SFR48/2016. Retrieved from https://www.gov.uk/government/statistics/gcse-and-equivalent-results2015-to-2016-provisional. Accessed 11 May 2018.

Dockrell, J. E., \& Connelly, V. (2015). The role of oral language in underpinning the text generation difficulties in children with specific language impairment. Journal of Research in Reading, 38(1), 18-34. https://doi.org/10.1111/j.1467-9817.2012.01550.x.

Dockrell, J. E., Ricketts, J., Charman, T., \& Lindsay, G. (2014). Exploring writing products in students with language impairments and autism spectrum disorders. Learning and Instruction, 32, 81-90.

Dodd, B., \& Carr, A. (2003). Young children's letter-sound knowledge. Language, Speech and Hearing Serviced in Schools, 34, 128-137. https://doi.org/10.1044/0161-1461(2003/011).

Dunn, L. M., Dunn, D. M., \& NFER-Nelson. (1997). The British picture vocabulary scale. London: NFER-Nelson.

Early, D. M., Iruka, I. U., Ritchie, S., Barbarin, O. A., Winn, D.-M. C., Crawford, G. M., et al. (2010). How do pre-kindergarteners spend their time? Gender, ethnicity, and income as predictors of experiences in pre-kindergarten classrooms. Early Childhood Research Quarterly, 25(2), 177-193. https://doi.org/10.1016/j.ecresq.2009.10.003.

Engle, R. W., Tuholski, S. W., Laughlin, J. E., \& Conway, A. R. (1999). Working memory, short-term memory, and general fluid intelligence: A latent-variable approach. Journal of Experimental Psychology: General, 128(3), 309. https://doi.org/10.1037/0096.3445.128.3.309.

Fearrington, J. Y., Parker, P. D., Kidder-Ashley, P., Gagnon, S. G., McCane-Bowling, S., \& Sorrell, C. A. (2014). Gender differences in written expression curriculum-based measurement in third through eighth grade students. Psychology in the Schools, 51(1), 85-96. https://doi.org/10.1002/pits.21733.

Fernyhough, C., \& Fradley, E. (2005). Private speech on an executive task: Relations with task difficulty and task performance. Cognitive Development, 20(1), 103-120. https://doi.org/10.1016/j.cogdev. 2004.11002.

Field, A. (2013). Discovering statistics using IBM SPSS statistics. London: Sage.

Flavell, J. H., Beach, D. R., \& Chinsky, J. M. (1966). Spontaneous verbal rehearsal in a memory task as a function of age. Child Development, 37(2), 283-299.

Fraser, J., \& Conti-Ramsden, G. (2008). Contribution of phonological and broader language skills to literacy. International Journal of Language \& Communication Disorders, 43(5), 552-569.

Galsworthy, M. J., Dionne, G., Dale, P. S., \& Plomin, R. (2000). Sex differences in early verbal and nonverbal cognitive development. Developmental Science, 3(2), 206-215. https://doi.org/10.1111/14677687.00114.

Gathercole, S. E. (1998). The development of memory. Journal of Child Psychology and Psychiatry, 39(1), 3-27.

Gathercole, S. E., Willis, C., Emslie, H., \& Baddeley, A. (1991). The influences of number of syllables and wordlikeness on children's repetition of nonwords. Applied Psycholinguistics, 12, 349-367. https://doi.org/10.1017/S0142716400009267.

Goldstein, J. M., Jerram, M., Poldrack, R., Anagnoson, R., Breiter, H. C., Makris, N., et al. (2005). Sex differences in prefrontal cortical brain activity during fMRI of auditory verbal working memory. Neuropsychology, 19(4), 509-519. https://doi.org/10.1037/0894-4105.19.4.509.

Graham, S., Berninger, V. W., Abbott, R. D., Abbott, S. P., \& Whitaker, D. (1997). Role of mechanics in composing of elementary school students: A new methodological approach. Journal of Educational Psychology, 89(1), 170. https://doi.org/10.1037/0022-0663.89.1.170.

Graham, S., \& Harris, K. (2000). The role of self-regulation and transcription skills in writing and writing development. Educational Psychologist, 35(1), 3-12. https://doi.org/10.1207/S15326985EP3501_2.

Gur, R. C., Richard, J., Calkins, M. E., Chiavacci, R., Hansen, J. A., Bilker, W. B., et al. (2012). Age group and sex differences in performance on a computerized neurocognitive battery in children age 8-21. Neuropsychology, 26(2), 251-265. https://doi.org/10.1037/a0026712. 
Halpern, D. F. (2012). The new science of cognitive sex differences. Trends in Cognitive Sciences, 18(1), 37-45. https://doi.org/10.1016/j.tics.2013.10.011.

Harrison, G. L., Goegan, L. D., Jalbert, R., McManus, K., Sinclair, K., \& Spurling, J. (2016). Predictors of spelling and writing skills in first-and second-language learners. Reading and Writing, 29(1), 69-89. https://doi.org/10.1007/s11145-015-9580-1.

Hayes, J. R. (2012). Modeling and remodeling writing. Written Communication, 29(3), 369-388. https:// doi.org/10.1177/0741088312451260.

Hecht, S. A., \& Greenfield, D. B. (2002). Explaining the predictive accuracy of teacher judgments of their students' reading achievement: The role of gender, classroom behavior, and emergent literacy skills in a longitudinal sample of children exposed to poverty. Reading and Writing: An Interdisciplinary Journal, 15, 789-809. https://doi.org/10.1023/A:102098570.

Hedges, L. V., \& Nowell, A. (1995). Sex differences in mental test scores, variability, and numbers of high-scoring individuals. Science, 269, 41-45.

Henry, L. A., Messer, D., Luger-Klein, S., \& Crane, L. (2012). Phonological, visual, and semantic coding strategies and children's short-term picture memory span. The Quarterly Journal of Experimental Psychology, 65(10), 2033-2053.

Hitch, G. J., Halliday, M. S., Dodd, A., \& Littler, J. E. (1989a). Development of rehearsal in short-term memory: Differences between pictorial and spoken stimuli. British Journal of Developmental Psychology, 7(4), 347-362. https://doi.org/10.1111/j.2044-835X.1989.t600811.x.

Hitch, G. J., Halliday, M. S., Schaafstal, A. M., \& Heffernan, T. M. (1991). Speech, "inner speech”, and the development of short-term memory: Effects of picture-labeling on recall. Journal of Experimental Child Psychology, 51(2), 220-234. https://doi.org/10.1016/0022-0965(91)90033-O.

Hitch, G. J., Woodin, M. E., \& Baker, S. (1989b). Visual and phonological components of working memory in children. Memory \& Cognition, 17(2), 175-185. https://doi.org/10.3758/BF03197067.

Hutcheson, G. D., \& Sofroniou, N. (1999). The multivariate social scientist: Introductory statistics using generalized linear models. London: Sage.

Hyde, J. S. (2014). Gender similarities and differences. Annual Review of Psychology, 65, 373-398. https://doi.org/10.1146/annurev-psych-010213-115057.

Hyde, J. S. (2016). Sex and cognition: Gender and cognitive functions. Current Opinion in Neurobiology, 38, 53-56. https://doi.org/10.1016/j.conb.2016.02.007.

Hyde, J. S., \& Linn, M. C. (1988). Gender differences in verbal ability: A meta-analysis. Psychological Bulletin, 104(1), 53-69. https://doi.org/10.1037//0033-2909.104.1.53.

Jewell, J., \& Malecki, C. K. (2005). The utility of CBM written language indices: An investigation of production-dependent, production-independent, and accurate-production scores. School Psychology Review, 34(1), 27-44.

Johnston, R., McGeown, S., \& Moxon, G. E. (2014). Towards an understanding of how children read and spell irregular words: The role of nonword and orthographic processing skills. Journal of Research in Reading, 37(1), 51-64. https://doi.org/10.1111/jrir.12007.

Jones, S., \& Myhill, D. (2007). Discourses of difference? Examining gender differences in linguistic characteristics of writing. Canadian Journal of Education. https://doi.org/10.2307/20466646.

Juel, C., Griffith, P. L., \& Gough, P. B. (1986). Acquisition of literacy: A longitudinal study of children in first and second grade. Journal of Educational Psychology, 78(4), 243. https://doi.org/10.1037/00230663.78.4.243.

Kaufer, D. S., Hayes, J. R., \& Flower, L. (1986). Composing written sentences. Research in the Teaching of English, 20(2), 121-140.

Kaushanskaya, M., Gross, M., \& Buac, M. (2013). Gender differences in child word learning. Learning and Individual Differences, 27, 82-89. https://doi.org/10.1016/j.lindif.2013.07.002.

Kellogg, R. T., Whiteford, A. P., Turner, C. E., Cahill, M., \& Mertens, A. (2013). Working memory in written composition: An evaluation of the 1996 model. Journal of Writing Research, 5(2), 159-190. https://doi.org/10.17239/jowr-2013.05.02.1.

Kent, S., Wanzek, J., Petscher, Y., Al Otaiba, S., \& Kim, Y.-S. (2014). Writing fluency and quality in kindergarten and first grade: The role of attention, reading, transcription, and oral language. Reading and Writing, 27(7), 1163-1188. https://doi.org/10.1007/s1145-013-9480-1.

Kim, Y.-S., Al Otaiba, S., Puranik, C., Folsom, J. S., Greulich, L., \& Wagner, R. K. (2011). Componential skills of beginning writing: An exploratory study. Learning and Individual Differences, 21(5), 517-525. https://doi.org/10.1016/j.lindif.2011.06.004. 
Kim, Y.-S., Al Otaiba, S., Folsom, J. S., Greulich, L., \& Puranik, C. (2014). Evaluating the dimensionality of first-grade written composition. Journal of Speech, Language, and Hearing Research, 57(1), 199-211. https://doi.org/10.1044/1092-4388(2014/12-01.52).

Kim, Y.-S., Al Otaiba, S., Wanzek, J., \& Gatlin, B. (2015a). Toward an understanding of dimensions, predictors, and the gender gap in written composition. Journal of Educational Psychology, 107(1), 79. https://doi.org/10.1037/a0037210.

Kim, Y.-S., Park, C., \& Park, Y. (2015b). Dimensions of discourse level oral language skills and their relation to reading comprehension and written composition: An exploratory study. Reading and Writing, 28(5), 633-654. https://doi.org/10.1007/s11145-015-9542-7.

Klassen, R. (2002). Writing in early adolescence: A review of the role of self-efficacy beliefs. Educational Psychology Review, 14(2), 173-203. https://doi.org/10.10233/A:101462680.

Knudson, R. E. (1995). Writing experiences, attitudes, and achievement of first to sixth graders. The Journal of Educational Research, 89(2), 90-97. https://doi.org/10.1080/0220671.1995.9941199.

Kramer, J. H., Delis, D. C., Kaplan, E., O’Donnell, L., \& Prifitera, A. (1997). Developmental sex differences in verbal learning. Neuropsychology, 11(4), 577-584. https://doi.org/10.1037/08944195.11.4.577.

Lee, J. A. C., \& Al Otaiba, S. (2015). Socioeconomic and gender group differences in early literacy skills: A multiple-group confirmatory factor analysis approach. Educational Research and Evaluation, 21(1), 40-59. https://doi.org/10.1080/13803611.2015.1010545.

Lejbak, L., Crossley, M., \& Vrbancic, M. (2011). A male advantage for spatial and object but not verbal working memory using the n-back task. Brain and Cognition, 76, 191-196. https://doi.org/10.1016/j. bandc.2010.12.002.

Leppanen, U., Aunola, K., Niemi, P., \& Nurmi, J.-E. (2008). Letter knowledge predicts Grade 4 reading fluency and reading comprehension. Learning and Instruction, 18, 548-564. https://doi.org/10.1016/ j.learninstruc.2007.11.004.

Limpo, T., \& Alves, R. A. (2013). Modeling writing development: Contribution of transcription and selfregulation to Portuguese students' text generation quality. Journal of Educational Psychology, 105(2), 401. https://doi.org/10.1037/a0031391.

Lundberg, I., Larsman, P., \& Strid, A. (2012). Development of phonological awareness during the preschool year: The influence of gender and socio-economic status. Reading and Writing, 25, 305-320. https://doi.org/10.1007/s11145-010-9269-4.

Mackie, C. J., Dockrell, J., \& Lindsay, G. (2013). An evaluation of the written texts of children with SLI: The contributions of oral language, reading and phonological short-term memory. Reading and Writing, 26(6), 865-888. https://doi.org/10.1007/s11145-012-9396-1.

Mäki, H. S., Voeten, M. J., Vauras, M. M., \& Poskiparta, E. H. (2001). Predicting writing skill development with word recognition and preschool readiness skills. Reading and Writing, 14(7), 643-672. https://doi.org/10.1023/A:101207151.

Malecki, C. K., \& Jewell, J. (2003). Developmental, gender, and practical considerations in scoring curriculum-based measurement writing probes. Psychology in the Schools, 40(4), 379-390. https:// doi.org/10.1002/pits.10096.

Mata, L. (2011). Motivation for reading and writing in kindergarten children. Reading Psychology, 32(3), 272-299. https://doi.org/10.1080/02702711.2010.545268.

McCutchen, D. (1996). A capacity theory of writing: Working memory in composition. Educational Psychology Review, 8(3), 299-325. https://doi.org/10.1007/BF01464076.

McCutchen, D. (2000). Knowledge, processing, and working memory: Implications for a theory of writing. Educational Psychologist, 35(1), 13-23. https://doi.org/10.1207/S1532698EP3501_3.

McCutchen, D. (2006). Cognitive factors in the development of children's writing. Handbook of Writing Research, 8, 115-130.

McCutchen, D., Covill, A., Hoyne, S. H., \& Mildes, K. (1994). Individual differences in writing: Implications of translating fluency. Journal of Educational Psychology, 86(2), 256. https://doi.org/ 10.1037/0022-0663-86.2.256.

Meece, J. L., Glienke, B. B., \& Burg, S. (2006). Gender and motivation. Journal of School Psychology, 44(5), 351-373. https://doi.org/10.1016/j.jsp.2006.04.004.

Morley, D., Till, K., Ogilvie, P., \& Turner, G. (2015). Influences of gender and socioeconomic status on the motor proficiency of children in the UK. Human Movement Science, 44, 150-156. https://doi. org/10.1016/j.humov.2015.08.022.

Muter, V., Hulme, C., \& Snowling, M. J. (1997). The phonological abilities test. London: The Psychological Corporation. 
Olinghouse, N. G. (2008). Student-and instruction-level predictors of narrative writing in third-grade students. Reading and Writing, 21(1-2), 3-26. https://doi.org/10.1007/s11145-007-9062-1.

Olive, T. (2004). Working memory in writing: Empirical evidence from the dual-task technique. European Psychologist, 9(1), 32-42. https://doi.org/10.1027/1016-9040.9.1.32.

Ouellette, G., \& Sénéchal, M. (2008). Pathways to literacy: A study of invented spelling and its role in learning to read. Child Development, 79(4), 899-913. https://doi.org/10.1111/j.1467-8624.2008. 01166.x.

Pajares, F., \& Valiante, G. (2001). Gender differences in writing motivation and achievement of middle school students: A function of gender orientation? Contemporary Educational Psychology, 26(3), 366-381. https://doi.org/10.1006/ceps.2000.1069.

Palmer, S. (2000a). Development of phonological recoding and literacy acquisition: A four-year crosssequential study. British Journal of Developmental Psychology, 18(4), 533-555. https://doi.org/10. 1080/096582100387597.

Palmer, S. (2000b). Working memory: A developmental study of phonological recoding. Memory, 8(3), 179-193. https://doi.org/10.1348/026151000165841.

Pargulski, J. R., \& Reynolds, M. R. (2017). Sex differences in achievement: Distributions matter. Personality and Individual Differences, 104, 272-278. https://doi.org/10.1016/paid.2016.08.016.

Persky, H. R., Dane, M. C., \& Jin, Y. (2003). The Nation's report card: Writing 2002 (NCES 2003-529). Washington, DC: National Center for Education Statistics. Retrieved from http://nces.ed.gov/ nationsreportcard.

Pickering, S., \& Gathercole, S. E. (2001). Working memory test battery for children (WMTB-C). London: Psychological Corporation.

Puranik, C. S., \& Al Otaiba, S. (2012). Examining the contribution of handwriting and spelling to written expression in kindergarten children. Reading and Writing, 25(7), 1523-1546. https://doi.org/10. 1007/s11145-011-9331-x.

Puranik, C. S., Lonigan, C. J., \& Kim, Y.-S. (2011). Contributions of emergent literacy skills to name writing, letter writing, and spelling in preschool children. Early Childhood Research Quarterly, 26(4), 465-474. https://doi.org/10.1016/j.ecresq.2011.03.002.

Reynolds, M. R., Scheiber, C., Hajovsky, D. B., Schwartz, B., \& Kaufman, A. S. (2015). Gender differences in academic achievement: Is writing an exception to the gender similarities hypothesis? The Journal of Genetic Psychology, 176(4), 211-234. https://doi.org/10.1080/00221325-20151036833.

Scheiber, C., Reynolds, M. R., Hajovsky, D. B., \& Kaufman, A. S. (2015). Gender differences in achievement in a large, nationally representative sample of children and adolescents. Psychology in the Schools, 52(4), 335-348. https://doi.org/10.1002/pits.21827.

Schmidt, H., Jogia, J., Fast, K., Christodoulou, T., Haldane, M., Kumari, V., et al. (2009). No gender differences in brain activation during the N-back task: An fMRI study in healthy individuals. Human Brain Mapping, 30, 3609-3615. https://doi.org/10.1002/hbm.20783.

Schneider, W., Roth, E., \& Ennemoser, M. (2000). Training phonological skills and letter knowledge in children at risk for dyslexia: A comparison of three kindergarten intervention programs. Journal of Educational Psychology, 92(2), 284-295. https://doi.org/10.1037//0022-0663.92.2.284.

Shanahan, T. (2006). Relations among oral language, reading, and writing development. In S. G. C. MacArthur \& J. Fitzgerald (Eds.), Handbook of writing research (pp. 171-183). New York: Guilford.

Swanson, H. L., \& Berninger, V. W. (1996). Individual differences in children's working memory and writing skill. Journal of Experimental Child Psychology, 63(2), 358-385. https://doi.org/10.1006/ jecp.1996.0054.

The British Psychological Society. (2014). Code of human research ethics. Retrieved from https://www. bps.org.uk/sites/beta.bps.org.uk/files/Policy\%20-\%20Files/Code\%20of\%20Human\%20Research\% 20Ethics\%20(2014).pdf. Accessed 11 May 2018.

Vanderberg, R., \& Swanson, H. L. (2007). Which components of working memory are important in the writing process? Reading and Writing, 20(7), 721-752. https://doi.org/10.1007/s11145-006-9046-6.

Wagner, R. K., Puranik, C. S., Foorman, B., Foster, E., Wilson, L. G., Tschinkel, E., et al. (2011). Modeling the development of written language. Reading and Writing, 24(2), 203-220. https://doi. org/10.1007/s11145-010-9266-7.

Wechsler, D. (2005). Wechsler individual achievement test, WIAT-II (UK). London: The Psychological Corporation. 
Williams, D., Happé, F., \& Jarrold, C. (2008). Intact inner speech use in autism spectrum disorder: Evidence from a short-term memory task. Journal of Child Psychology and Psychiatry, 49(1), 51-58. https://doi.org/10.1111/j.1469-7610.2007.01836x.

Williams, G. J., \& Larkin, R. F. (2013). Narrative writing, reading and cognitive processes in middle childhood: What are the links? Learning and Individual Differences, 28, 142-150. https://doi.org/10. 1016/j.lindif.2012.08.003.

Wilson, R. (2012). Big writing. Oxford: Oxford University Press.

Wilson, R. (2014). Big writing: Raising writing standards a powerful and effective whole-school approach. Oxford: Oxford University Press.

Wilson, R. (2016). Big Writing: Standards for writing assessment. Oxford: Oxford University Press. 